\title{
RESEARCH ON THE BUCKET BORE RENEWAL TECHNOLOGIES
}

\author{
RATKUS, A[ndris] \& TORIMS, T[oms]
}

\begin{abstract}
In-situ (mobile) repair technologies are used for specialised equipment and machinery repairs, as they offer considerable cost reductions and increase the technological lifespan of industrial equipment. Such parts as frames, joints or buckets can be renewed to an excellent standard using insitu technologies.

In-situ renovation technology is itself a non-conventional operation, even though the techniques of turning and installation are relatively well studied and developed. Conversely, build-up welding processes can be studied further and potentially substituted by more advanced and economically more viable, modern surface-renovation technologies.

Emphasis will be placed on cladding technologies. By examining the literature, the objective is to identify and justify the most appropriate surface-coating technology. The best results were achieved by Gas metal arc welding, Plasma arc welding and Laser cladding technologies. Experimental work will follow for these three technologies.

Key words: in-situ renovation, build-up welding technology, cladding, spraying
\end{abstract}

\section{INTRODUCTION}

This paper outlines the initial progress of the $\mathrm{PhD}$ thesis (ongoing). The overall aim of this study is to develop an economically viable, backhoe bucket renewal technology, using standard and enhanced technological approaches.

Any renewal technology has to meet high standards, because the output quality must offer comparable operating performance and durability to the new product. Furthermore, surface roughness, shape and tolerances have to be identical or even superior to manufacturers' standards. This requires an in-depth, systematic study of the pins and buckets bores, which are the most frequently renewed items. Finally, the aim is to provide an appropriate quality with a suitable insitu renewal technology.

It is important to note that the new material layer has to match or surpass the operational characteristics of a replacement part. It is therefore important to establish the most suitable technology from the available spectrum. Renewal operations such as turning and installation are relatively well studied and developed. For these operations, it is possible to adapt and use a wide range of turning and installation equipment and technologies. Therefore research efforts will mainly focus on the new material layer cladding operation. Moreover, there has been very little previous research and limited scope for relatively small bore (60$100 \mathrm{~mm}$ ) build-up technologies [3]. In this respect also therefore, the results from our research may potentially provide a greater understanding and highlight all the benefits of the analysed renewal technologies.

\section{RENEWAL TECHNOLOGY}

Conventional in-situ drilling and repair technologies are implemented by installing equipment directly on the damaged product (Fig.1.) using specialised centring devices. The bore's central axis is used as a basis for positioning.

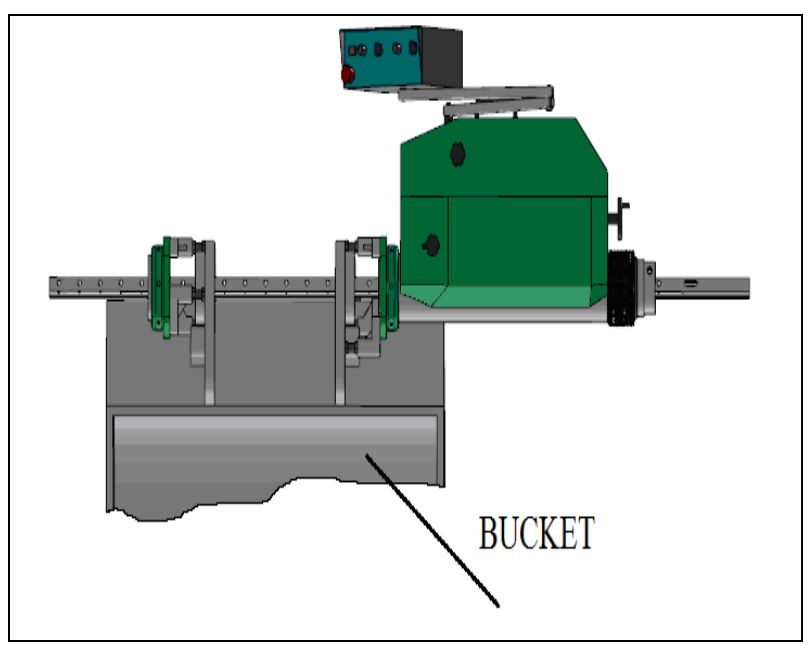

Fig. 1. Renewal equipment on damaged bucket [3]

The damaged layer is then removed mechanically by means of a turning operation. Once this is complete, the surface to be renewed is covered with a new layer of material using conventional MIG/MAG welding (Fig.2.). This is followed by the final operation: turning to the nominal bore size.

Conventional MIG/MAG (GMAW) welding technology is one of the cheapest new layer build-up techniques and is therefore most widely used. 
Furthermore it is easy to adapt this build-up technology for inner surface (bore) cladding.

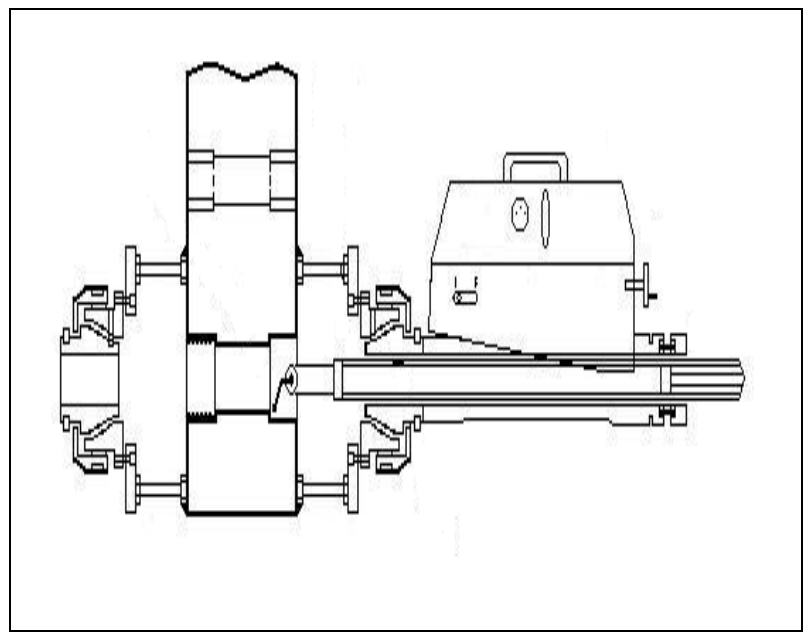

Fig. 2. MIG/MAG (GMAW) build-up welding equipment [6]

\section{COATING TECHNOLOGIES ANALYSIS}

Designing a suitable surface treatment from a given combination of loads poses certain challenges. Not only is it often difficult to precisely and thoroughly understand the operating conditions of a part, but also a very wide range of potential materials and material technology processes have to be considered. Selecting an appropriate technology to produce a certain combination of surface characteristics is a highly complex process. It involves the systematic correlation of specifications with attainable surface properties. Usually, the selection process includes both economic and ecological evaluations [2].

All coating technologies fall into two main groups: coating by conventional welding and surface-spraying technologies. In addition, several other technologies exist for creating a new layer of metal, by means of powder metallurgy. A bush insert can also be used to create a new metal layer.

These various technologies all imply different technological processes, power sources, filler materials and results.

\subsection{Build-up welding}

Build-up welding (Fig. 3.) is a technique whereby a coating is applied during a fully or partially molten phase. A metallurgical bond between the coating and substrate material is created when both the substrate and coating materials are melted [2].

In principle, all welding techniques are suitable for build-up welding. During the historical development of welding technology, each welding technique has been used for build-up welding. Nowadays, owing to process characteristics, certain welding processes or variants have become particularly popular [2].
Compared to other deposition techniques, build-up welding generally produces coatings with higher adhesion, due to the metallurgical bond created by the partially or fully molten materials. The join between the coating and substrate is never the weakest area of the compound, as long as adhesion-reducing hard phases, produced by inadequate combinations of coating and substrate material, are avoided. These coatings are therefore particularly suited to applications where the renewed parts are subject to heavy wear. Additionally, they offer high edge strength $[2,5]$.

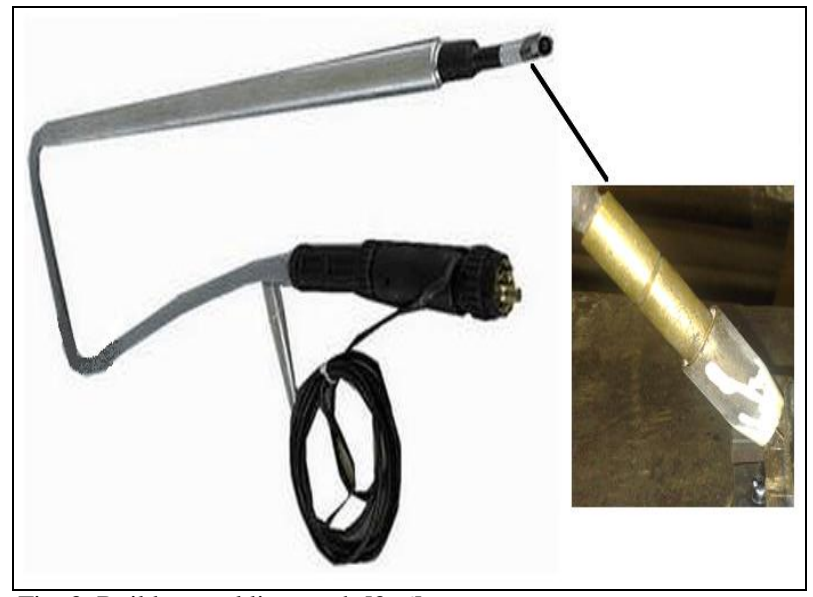

Fig. 3. Build-up welding torch [3, 6]

Build-up technologies [1, 2, 5]:

1. Submerged arc welding (SAW).

2. Shielded metal arc welding (SMAW).

3. Gas metal arc welding (GMAW).

4. Flux Cored Arc Welding (FCAW).

5. Plasma arc welding (PAW).

6. Light amplification by stimulated emission of radiation (LASER).

\subsection{Thermal spraying}

Thermal spraying (Fig. 4.) processes offer coatings for parts using a diverse range of coating materials to enhance wear and corrosion resistance, as well as providing a thermal barrier or producing the desired electrical or magnetic properties, etc. The basic principle and definition of the term thermal spraying is standardised in DIN EN 657. The material to be sprayed is fed to a source of heat in the form of powder, wire or rod, inside or outside the spray apparatus. Here it is melted superficially or completely, or heated until it is sufficiently soft. A gas stream projects the particles onto the substrate, where they are deposited as a coating [2].

Thermal spraying technologies [1, 2, 4]:

1. Plasma spraying; 
2. Plasma transferred wire arc (PTWA);

3. Wire flame spraying;

4. High velocity oxy-fuel coating spraying (HOVOF);

5. Cold spraying;

6. Warm spraying;

7. Arc spraying;

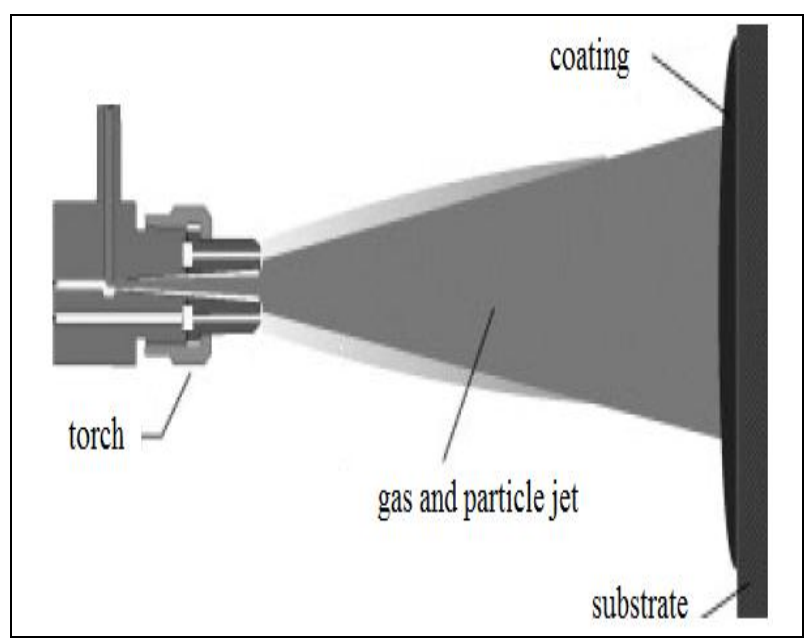

Fig. 4. Principle of thermal spraying [2]

\section{MAIN RESEARCH TOPICS}

The first step is to establish the frame of reference for build-up cladding, based on the properties and features of the renewal technology. Secondly, a comprehensive literature review/research is required in order to identify as many cladding technologies as possible.

Thirdly, we have to identify and justify the most appropriate surface coating technology.

The following main criteria (properties and features of the renewal technology) will be used within this comparative study:

1. Thickness of the build-up layer (up to $1.5 \mathrm{~mm}$ ).

2. Potential for in-situ application of the renovation technology.

3. Potential for cladding and spraying in all torch positions and directions.

4. Bore size limits (min. 60-100 mm).

5. Possibility to use technology for inner surfaces.

These are the main criteria. Further in-depth research of the literature was conducted for the technologies that fulfilled all five criteria. The results are shown in Fig.5. Ten technologies comply with the conditions, which is too many for an in-depth review.

Therefore additional criteria had to be identified with which to assess the technologies and compare their values.
Additional criteria:

1. Deposition rate $(\mathrm{kg} / \mathrm{h})$.

2. Deposition efficiency $(\%)$.

3. Dilution (\%).

4. Porosity (\%).

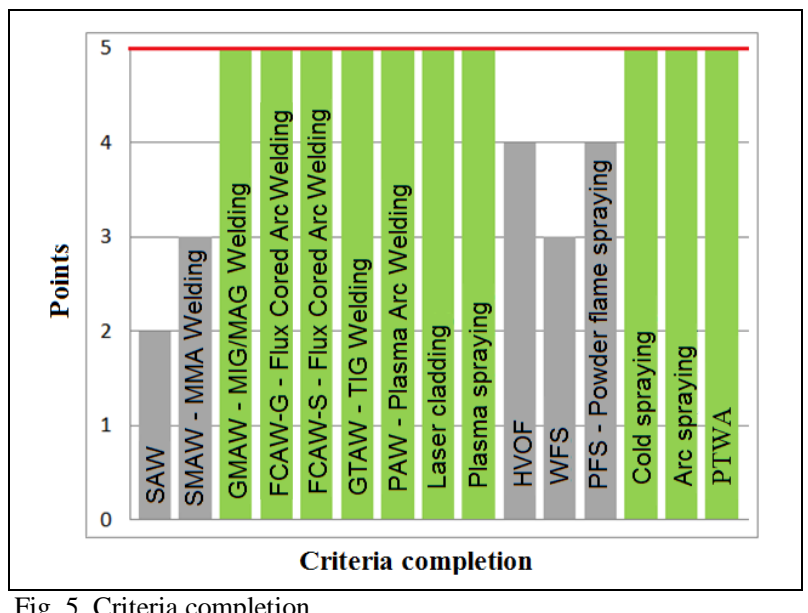

Fig. 5. Criteria completion

For the assessment, it was necessary to establish a scoring system where, for each criterion, the maximum value would be 1 point and the minimum 0 .

The results are shown in Fig.6. The best results following this second assessment were:

1. Arc spraying, 3.49 points.

2. Plasma arc welding, 3.42 points.

3. Gas metal arc welding, 3.34 points.

4. Flux cored arc welding - gas-shielded, 3.30 points.

5. Flux cored arc welding - self-shielded, 3.24 points.

6. Laser cladding, 3.06 points.

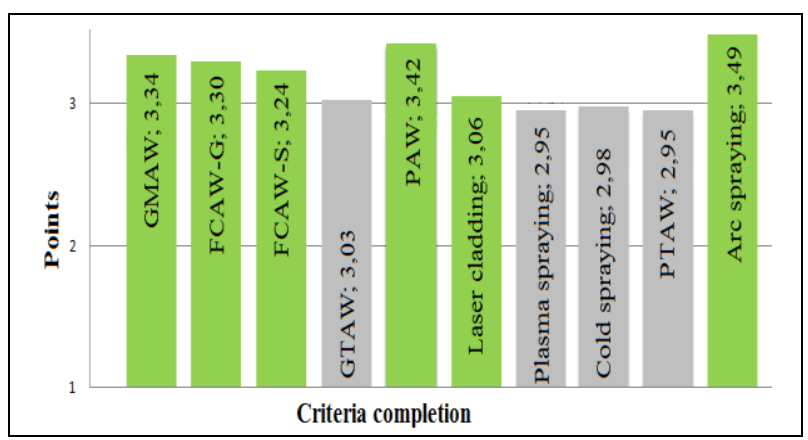

Fig. 6. Scores after additional criteria

\subsection{Arc spraying}

In arc spraying, two wires of the same or different material (pseudo-alloy) are fed to the spray gun. The wire feed rate is controlled. Electrical energy is usually transmitted via copper contacting wire feeds, arranged at a $30^{\circ}$ angle. When the wire feeds are running, the spray wires move towards each other until they touch. Temperatures within the arc rise to $6,500^{\circ} \mathrm{C}$. The material melts down and its particles are atomised, accelerated, and deposited on the surface to be coated, by means of gas projected from the nozzle (usually compressed air). The process can be conducted 
similarly using three or four wires, which is referred to as multi-wire arc spraying with high deposition rate $(\mathrm{kg} / \mathrm{h})[2]$.

The high temperature at the wire ends can cause their combustion and loss of alloying elements in the spray material. For elements such as silicon or manganese, the loss can be up to $40 \%$, whilst for other elements, e.g. carbon, it may even be $60 \%$. These elements are found in small quantities in the wires [2]. Therefore, this technology was eliminated from the potential technologies' list.

\subsection{Plasma arc welding}

Build-up welding by means of a plasma jet differs from plasma spraying in that an arc burns between the torch and the workpiece (transferred arc). This directly contributes to heating up the workpiece. The power density here is the highest for all conventional welding processes and leads to concentrated heat input into the workpiece. Fusion penetration can thus be limited to $10 \%$ for steel [2].

Plasma arc build-up welding technology will therefore be studied further.

\subsection{Gas metal arc welding}

Gas-shielded metal arc welding (GMAW) is achieved by means of a consumable wire electrode of coating material. A positive charge is applied to the electrode in order to yield sufficient wire melt-off. Consumables are fed to the torch by wire-feeding equipment via a bundle of tubes from a wire coil. Certain sensitive materials with reduced strength or cored wires require an additional feeding system inside the torch (push-pull systems). The electrical current is conducted through a contacting tube. The arc burns between the wire and the electrode, heats the workpiece and melts down the wire. This technique has a high fusion penetration that can reach up to $30 \%$. Specific torch positioning (arc root set onto previous bead) and additional cold wire feeding can limit the fusion penetration by up to $5 \%$. The application of powdery consumables is currently also under investigation [2].

FCAW-G and FCAW-S are similar technologies to GMAW. They require almost identical equipment and consumables, the only difference being the wire. For these technologies therefore, all research and experiments can be grouped together.

\subsection{Laser cladding}

The laser beam is transmitted to the weld by means of encapsulated beam lead systems (CO2 laser) or along fibre optic cables with focusing lenses. Owing to the high power density, an out-of-focus operation is frequently necessary in order to prevent alloying elements in the coating material from overheating. Consumables can be applied as wires, cored wires or powders via powder feeders. The coating thickness can be up to $2 \mathrm{~mm}$. Current developments in the field of laser cladding include hand-operated laser processing heads that allow, for instance, the refurbishing of slight abrasion marks on forming or cutting tools without depositing excessive material on the surface. Systems can be automated to compensate for unsteady motion during the manual operation [2].

After further analysis, this technology also proved suitable for the renewal operation.

\section{CONCLUSIONS}

This article describes the conclusion of the in-depth literature review, which made it possible to identify the most suitable build-up technology for industrial bucket bore renewal. Clear and understandable evaluation criteria were used and this enabled us to conclude that research should continue in the direction of GMAW (with FCAW-G and FCAW-S), PAW and LASER build-up technologies. These three technologies fulfil the initial evaluation criteria and shall be analysed further, including in laboratory experiments and test trials, to identify their adhesive strength (MPa) and heat-affected zone (HAZ) (mm, \%).

\section{REFERENCES}

[1] Chattopadhyay R. (2004). Advanced Thermally Assisted Surface Engineering Processes, Springer, Kluwer Academic Publishers, ISBN: 978-1402076961 Hingham, USA

[2] Fr.-W. Bach, A. Laarmann, T. Wenz (eds.). (2006). Modern Surface Technology, Wiley-VCH Verlag GmbH \& Co. ISBN: 3-527-31532-2, KGaA, Weinheim

[3] Ratkus A. (2011). Master's thesis: Research on Bucket Bore Renewal Technologies, Riga

[4] Robert B. Heimann. (2008). Plasma-Spray Coating: Principles and Applications, ISBN: 978-3-527-32050-9 John Wiley \& Sons, Weinheim

[5] R. L. O’Brien (ed.) (1997). Welding Handbook, Eighth Edition, Vol. 2. Welding Processes, American Welding Society, Miami

[6] http://elsasrl.com/img/download-catalogo-macchine-utensiliportatili/supercombinata-sc1-en-informazioni-tecniche.pdf, (2011). Elsa S.r.l. catalog, Accessed on: 2012-03-12 